\title{
Perancangan Model Pembelajaran Computational Thinking Jarak Jauh menggunakan Teknologi Block Programming bagi Calon Mahasiswa Baru di masa Pandemi Covid-19
}

\author{
Bernardinus Harnadi ${ }^{\# 1}$, Agus Cahyo Nugroho*2 \\ "Sistem Informasi, Unika Soegijapranata \\ Jl. Pawiyatan Luhur IV/I Bendan Dhuwur, Semarang 50234 \\ ${ }^{1}$ bharnadi@unika.ac.id \\ *Sistem Informasi, Unika Soegijapranata \\ Jl. Pawiyatan Luhur IV/I Bendan Dhuwur, Semarang 50234 \\ 2agus.nugroho@unika.ac.id
}

\begin{abstract}
Abstrak-Pengabdian masyarakat ini bertujuan melakukan investigasi penggunaan teknologi "Block Programming" yang cocok bagi perancangan pembelajaran "Computational Thinking" jarak jauh bagi Calon Mahasiswa Baru terutama di masa Pandemi Covid-19. Pembelajaran jarak jauh disini terkait dengan pelarangan pembelajaran tatapmuka selama masa pandemi Covid-19. Alat bantu dalam mewujudkan tujuan pengabdian masyarakat ini terdiri dari aplikasi MIT App Inventor-2 untuk mengkonstruksi teknologi Block Programming, perancangan modul pembelajaran berbasis Computational Thinking dengan teknologi Block Programming yang ada di aplikasi MIT App Inventor-2, dan perancangan model pembelajaran jarak jauh dengan media internet dan aplikasi Anydesk. Hasil dari pengabdian masyarakat ini berupa model pembelajaran "Computational Thinking" jarak jauh yang sudah diterapkan di Program Studi Sistem Informasi. Penerapan ini diharapkan mampu menyiapkan generasi muda penerus yang mampu menjadi produsen dan innovator teknologi di masa depan. Sebagai generasi yang akan menentukan alih ilmu pengetahuan dan teknologi di masa depan, pendidikan berpikir komputasional ini ke mereka memiliki nilai strategis yang sangat penting.
\end{abstract}

Kata kunci-model pembelajaran, computational thinking, jarak jauh, block programming, covid-19.

Abstract-This community service aims to investigate the use of "Block Programming" technology which is suitable for designing distance learning "Computational Thinking" for Prospective New Students, especially during the Covid-19 Pandemic. Distance learning here is related to the prohibition of face-to-face learning during the Covid-19 pandemic. The tools in realizing this community service goal consist of the MIT App Inventor-2 application to construct Block Programming technology, the design of Computational Thinking-based learning modules with Block Programming technology in the MIT App Inventor-2 application, and the design of distance learning models using media. internet and the Anydesk app. The result of community service is in the form of a remote "Computational Thinking" learning model that has been applied in the Information Systems Study Program. This application is expected to be able to prepare the next generation of young people who are able to become technology producers and innovators in the future. As the generation that will determine the transfer of science and technology in the future, this computational thinking education to them has a very important strategic value.

Keywords — learning models, computational thinking, distance, block programming, covid-19.

\section{PENDAHULUAN}

Generasi muda merupakan tulang punggung kemajuan bangsa yang salah satunya berupa kemampuan penguasaan teknologi maju. Kemampuan penguasaan teknologi maju tidak terlepas dari Pendidikan yang didasarkan pada kemampuan berfikir secara nalar dan logis dan mampu melakukan komputasi (Computational Thinking) terhadap permasalahan kehidupan dan pembangunan [1],[2],[3]. Kemampuan tersebut perlu dilatih sejak dini pada Calon Mahasiswa Baru. 
Pembekalan kemampuan computational thinking yang dipadukan dengan kemampuan pemrograman dasar di bidang teknologi informasi memberikan efek ganda pada pembiasaan anak-anak usia sekolah dasar dengan teknologi informasi dan komunikasi yang akan sekaligus menyiapkan mereka menjadi produsen dan innovator-inovator teknologi dan bukan hanya pemakai atau konsumen teknologi [4],[5],[6]. Teknologi Block Programming merupakan teknologi pemrogram blok berbasis visual yang mudah dipelajari dan dikuasai oleh pengguna pemula karena membebaskan mereka dari kendala struktur kode dan sintaksis pemrograman [7],[8]. Terbebas dari kendala ini berarti mereka terlepas dari kesulitan terhadap kerumitan dan penguasaan konsep di dalam pemrograman [9],[10].

Tujuan dari pengabdian masyrakat ini adalah melakukan investigasi penggunaan teknologi Block Programming yang cocok bagi perancangan pembelajaran Computational Thinking jarak jauh bagi Calon Mahasiswa Baru terutama di masa Pandemi Covid-19. Pembelajaran jarak jauh disini terkait dengan pelarangan pembelajaran tatapmuka selama masa pandemic Covid-19. Cara berpikir komputasional sangat cocok dan sebaiknya diberikan kepada generasi penerus bangsa sejak dini atau diberikan sejak pendidikan dasar.

\section{METODE}

Pengabdian masyarakat ini terdiri dari tahapan pelaksanaan sebagai berikut: investigasi konsep computational thinking, review teknologi Block Programming, perancangan modul pembelajaran computational thinking dengan menggunakan teknologi Block Programming, dan uji coba model pembelajaran jarak jauh Computational Thinking dengan menggunakan teknologi Block Programming.

Langkah pertama adalah melakukan investigasi konsep Computational Thinking yang cocok bagi Calon Mahasiswa Baru. Berikutnya mereview teknologi Block Programming yang dapat membantu pembelajaran Computational Thinking untuk Calon Mahasiswa Baru. Setelah mendapatkan pilihan teknologi Block Programming yang dapat digunakan bagi penerapan konsep Computational Thinking yang cocok bagi pembelajaran pemula, maka dirancang modul pembelajarannya dengan mengadopsi kedua hal tersebut. Selanjutnya mengujicoba model pembelajaran tersebut pada Calon Mahasiswa Baru dengan konsep pembelajaran jarak jauh. Dan yang terakhir melakukan analisa hasil uji coba dan mengemasnya dalam laporan.

\section{HASIL DAN PEMBAHASAN}

Daftar pertanyaan kuesioner dari kegiatan pengabdian masyarakat ini bisa kita lihat pada Tabel 1. Pilihan jawaban responden disediakan dari skala 5 (sangat puas) hingga skala 1 (sangat tidak puas). Namun responden hanya menjawab dari skala 5 hingga skala 3 saja sehingga hanya data tersebut yang disajikan di Tabel 1 .

\section{TABEL I}

\begin{tabular}{|l|l|l|l|l|}
\hline No & Pertanyaan & $\begin{array}{l}\text { Jumlah } \\
\text { Jawaban } \\
\text { Skala 5 }\end{array}$ & $\begin{array}{l}\text { Jumlah } \\
\text { Jawaban } \\
\text { Skala 4 }\end{array}$ & $\begin{array}{l}\text { Jumlah } \\
\text { Jawaban } \\
\text { Skala 3 }\end{array}$ \\
\hline 1. & $\begin{array}{l}\text { Apakah materi yang } \\
\text { disampaikan } \\
\text { menambah wawasan } \\
\text { kamu? }\end{array}$ & 17 & 4 & 3 \\
\hline 2. & $\begin{array}{l}\text { Penilaian kamu } \\
\text { untuk platform } \\
\text { elearning.unika.ac.id } \\
\text { yang digunakan } \\
\text { kegiatan kursus ini? }\end{array}$ & 14 & 6 & 4 \\
\hline 3. & $\begin{array}{l}\text { Apakah teknis } \\
\text { pengelolaan dan } \\
\text { pelayanan } \\
\text { penyelenggara } \\
\text { kegiatan kursus ini } \\
\text { sudah baik? }\end{array}$ & 14 & 7 & 3 \\
\hline
\end{tabular}

Berdasarkan hasil kuesioner pada Tabel 1 bisa kita simpulkan bahwa 17 peserta merasa sangat puas terhadap materi yang disampaikan. 14 peserta merasa sangat puas terhadap kinerja platform elearning.unika.ac.id. 14 peserta merasa sangat puas terhadap teknis pengelolaan kegiatan ini. 4 peserta merasa puas terhadap materi yang disampaikan. 6 peserta merasa puas terhadap kinerja platform elearning.unika.ac.id. 7 peserta merasa puas terhadap teknis pengelolaan kegiatan ini. 3 peserta merasa biasa terhadap materi yang disampaikan. 4 peserta merasa biasa terhadap kinerja platform elearning.unika.ac.id. 3 peserta merasa biasa terhadap teknis pengelolaan kegiatan ini.

Selain pertanyaan pilihan pada kuesioner yang dibagikan juga meminta saran, pesan dan kesan dari para peserta. Daftar saran dari para peserta bisa kita lihat pada Tabel 2.

TABEL 2 


\begin{tabular}{|c|c|}
\hline No & Saran untuk Platform elearning.unika.ac.id \\
\hline 1. & $\begin{array}{l}\text { Semoga makin banyak kursus - kursus yang berguna } \\
\text { nantinya! }\end{array}$ \\
\hline 2. & Cukup bagus, tetapi bisa agak dikurangi untuk web error nya. \\
\hline 3. & Sudah sangat baik. \\
\hline 4. & Cukup baik. \\
\hline 5. & Sudah bagus. \\
\hline 6. & Menjaga koneksi tetap stabil. \\
\hline 7. & Membuat bagian presensi lebih baik. \\
\hline 8 . & Platform sudah berjalan dengan baik dan lancer. \\
\hline 9. & $\begin{array}{l}\text { Minta tolong untuk memperbaiki kualitas suaranya..terkadang } \\
\text { suaranya agak kurang enak didengar. }\end{array}$ \\
\hline 10. & $\begin{array}{l}\text { Platform ini harus tetap ada karena membantu kami camaba } \\
\text { baru mendapatkan ilmu:) }\end{array}$ \\
\hline 11. & $\begin{array}{l}\text { Sudah baik sekali untuk elearning.unika.ac.id sangat mudah } \\
\text { digunakan dan tidak ribet. }\end{array}$ \\
\hline 12. & $\begin{array}{l}\text { Desain platformnya bagi saya yang sedikit kurang menarik, } \\
\text { selain itu cukup sih.. }\end{array}$ \\
\hline 13. & Sudah baik. \\
\hline 14. & Kualitas video diperbaiki lagi. \\
\hline 15 . & $\begin{array}{l}\text { Terkadang masih sering tidak keluar suara untuk beberapa } \\
\text { peserta, jadi mungkin bisa ditinjau ulang permasalahannya. }\end{array}$ \\
\hline 16. & Dipermudah lagi dalam hal login ke web tersebut. \\
\hline 17. & Sudah sangat baik. \\
\hline 18. & Kedepannya bisa jauh lebih baik. \\
\hline 19. & $\begin{array}{l}\text { Platform e-learning sudah sangat bagus, dari segi efektifitas } \\
\text { dan performa sudah sangat memuaskan, memberi tampilan } \\
\text { yang lebih menarik maka mahasiswa akan enjoy. }\end{array}$ \\
\hline 20. & $\begin{array}{l}\text { Sudah bagus kak, tapi mungkin lebih dipermudah pada saat } \\
\text { absennya kak. }\end{array}$ \\
\hline 21. & $\begin{array}{l}\text { Platform elearning.unika.ac.id sudah baik. Saran tampilan } \\
\text { dibuat lebih menarik. }\end{array}$ \\
\hline 22. & Dibuat lebih simple \& menarik lagi tampilannya. \\
\hline 23. & $\begin{array}{l}\text { Saran saya untuk kegiatan elearningnya lebih sering diadakan. } \\
\text { Bukan hanya untuk mahasiswa saja melainkan untuk temen" } \\
\text { yang lain juga. }\end{array}$ \\
\hline 24. & Sudah bagus. \\
\hline
\end{tabular}

Berdasarkan saran dari para peserta pada Tabel 2 bisa kita simpulkan bahwa apresiasi peserta baik terhadap kegiatan ini. Hal ini terbukti peserta memberikan saran yang berharga untuk kegiatan ke depannya.

Sementara itu daftar pesan dan kesan dari para peserta bisa kita lihat pada Tabel 3 .

\section{TABEL 3}

\begin{tabular}{|l|l|}
\hline No & Pesan dan kesan selama mengikuti kegiatan ini \\
\hline 1. & $\begin{array}{l}\text { Tidak menyangka kalau ternyata membuat aplikasi ini ada } \\
\text { versi lebih mudahnya karena kebanyakan pakai coding. } \\
\text { Kedepannya, semoga makin banyak kursus" yang bisa } \\
\text { diaplikasi nantinya. }\end{array}$ \\
\hline
\end{tabular}

\begin{tabular}{|c|c|}
\hline 2. & $\begin{array}{l}\text { Asik, sangat menambah wawasan, semoga tahun depan } \\
\text { diadakan lagi untuk Camaba. }\end{array}$ \\
\hline 3. & Asik, tidak membosankan. \\
\hline 4. & Bagus si, nambah pengalaman juga. \\
\hline 5. & Semoga lebih baik kedepannya dan banyak camaba yg ikut. \\
\hline 6. & Asik. \\
\hline 7. & $\begin{array}{l}\text { Dosen menjelaskan kepada calon mahasiswa cara step by step } \\
\text { dengan jelas dan mudah dimengerti. }\end{array}$ \\
\hline 8. & Menambah wawasan dan mudah dipelajari. \\
\hline 9. & $\begin{array}{l}\text { Sangat berkesan. Pengajarnya sangat sabar dan baik. Kami } \\
\text { juga bisa menerima pembelajaran dengan baik bahkan } \\
\text { kakaknya pun jg ramah. }\end{array}$ \\
\hline 10. & $\begin{array}{l}\text { Setelah mengikuti kursus ini langsung bisa mempraktikkan } \\
\text { sendiri untuk mengisi waktu luang. Tetap adakan kegiatan } \\
\text { seperti ini karena akan dibutuhkan untuk terjun ke dunia } \\
\text { pekerjaan. }\end{array}$ \\
\hline 11. & $\begin{array}{l}\text { Menambah wawasan saya didunia SI dan ternyata SI juga ga } \\
\text { kalah menyenangkan, seru! }\end{array}$ \\
\hline 12. & Cukup Bagus dan Menarik. \\
\hline 13. & Seru. \\
\hline 14. & Sangat sulit di pahami...tapi ini jg menambah ilmu juga. \\
\hline 15. & $\begin{array}{l}\text { Saya merasa dengan kursus online ini bisa menambah } \\
\text { wawasan ketika berada di rumah saja, dan bisa mengisi waktu } \\
\text { luang ketika pandemi. Pesan saya untuk terus membuat kursus } \\
\text { online yang bisa menambah wawasan dan pengetahuan umum } \\
\text { selama di rumah saja. }\end{array}$ \\
\hline 16. & $\begin{array}{l}\text { Kursus ini sangat menambah wawasan dan pengetahuan } \\
\text { tentang aplikasi. }\end{array}$ \\
\hline 17. & $\begin{array}{l}\text { Pesannya supaya kualitas suara dan gambarnya ditingkatkan } \\
\text { lagi. }\end{array}$ \\
\hline 18. & $\begin{array}{l}\text { Baru pertama kali ikut kursus online seperti ini, dan ternyata } \\
\text { seru juga, menambah ilmu, dan pembawa materi ya juga sangat } \\
\text { sabar dan mudah dipahami dalam menjawab pertanyaan" yg } \\
\text { diberikan. }\end{array}$ \\
\hline 19. & $\begin{array}{l}\text { Bisa mengenal dosen dan teman-teman dari berbagai macam } \\
\text { fakultas yang berbeda, next bikin grup untuk angkatan } 20 \text { di } \\
\text { sistem informasi hehe. }\end{array}$ \\
\hline 20. & $\begin{array}{l}\text { Sangat bangga dapat merasakan kelas di bangku perkuliahan } \\
\text { walaupun dalam masa pandemi covid-19, sehingga tidak perlu } \\
\text { khawatir kita tertular covid-19, karena kita belajar melalui } \\
\text { platform yang sangat keren yang dapat kita akses dengan } \\
\text { mudah, kita belajar mengenai pembuatan dasar - dasar aplikasi } \\
\text { android secara cepat tetapi mudah untuk dipahami dan di } \\
\text { praktikan melalui aplikasi programing MIT App Inventor. }\end{array}$ \\
\hline 21. & $\begin{array}{l}\text { Kesannya pasti sangat menyenangkan kak, karna menambah } \\
\text { wawasan kita, ga sesusah yg dibayangin ternyata, lebih mudah, } \\
\text { dan cara penyampaian yg disampaikan oleh pemateri juga }\end{array}$ \\
\hline
\end{tabular}




\begin{tabular}{|l|l|}
\hline & $\begin{array}{l}\text { mudah dipahami, pesannya cuma 1 kak, semoga untuk } \\
\text { pengisian absen lebih diperjelas lagi ya kak, karna jujur } \\
\text { kemarin saya agak bingung, saya sudah mengikuti pertemuan } \\
1 \text { dan 2 tetapi disana tulisannya saya baru mengikuti 1 sesi } \\
\text { kalau tidak salah, maaf panjang banget kak pesannya. }\end{array}$ \\
\hline 22. & $\begin{array}{l}\text { Kesanku mengenai kegiatan kursus online ini adalah } \\
\text { kursusnya menyenangkan, kakak-kakak pembimbing juga } \\
\text { membantu jika ada kendala dengan senang hati. Menambah } \\
\text { wawasan saya mengenai aplikasi MIT. Pesannya adalah } \\
\text { mungkin diadakan game beberapa kali. }\end{array}$ \\
\hline 23. & $\begin{array}{l}\text { Kesannya ya bisa nambah wawasan dan untuk penyampaian } \\
\text { materinya mudah di tangkap. }\end{array}$ \\
\hline 24. & $\begin{array}{l}\text { Kesan: Kursus ini sangat menarik karena saya } \\
\text { belajar hal baru yang belum pernah saya buat. }\end{array}$ \\
Pesan: Kita perlu belajar hal yang baru untuk \\
menambah pengetahuan.
\end{tabular}

Banyak pesan dan kesan positif yang disampaikan oleh peserta setelah mengikuti kegiatan ini. Hal ini berarti tujuan awal pelaksanaan kegiatan ini sudah tercapai yaitu peserta dari berbagai latar belakang yang berbeda-beda bisa belajar membuat aplikasi dengan cara yang mudah. Selain itu platform elearning.unika.ac.id juga terbukti mampu memfasilitasi pembelajaran jarak jauh akibat pandemi Covid-19.

\section{DAFTAR PUSTAKA}

[1] David Bau, "Droplet, a blocks-based editor for text code," Journal of Computing Sciences in Colleges, pp. 138-144, 2015.

[2] David Bau, D Anthony Bau, Mathew Dawson, and C Pickens, "Pencil code: block code for a text world," In Proceedings of the 14th International Conference on Interaction Design and Children. ACM, pp. 445-448, 2015.

[3] Yizhou Qian and James Lehman, "Students' misconceptions and other difficulties in introductory programming: a literature review," $A C M$ Transactions on Computing Education (TOCE), 2017.

[4] Cansu, Fatih \& Cansu, Sibel. (2019). An Overview of Computational Thinking. International Journal of Computer Science Education in Schools. 3. 3. 10.21585/ijcses.v3i1.53.

[5] Weintrop, D. (2019). Block-based programming in computer science education. Communications of the ACM, 62(8), 22-25.

[6] Kong, S. C., \& Abelson, H. (Eds.). (2019). Computational Thinking Education. Springer.

[7] Kang, H., Cho, J., \& Kim, H. (2015). Application study on Android application prototyping method using App inventor. Indian Journal of Science and Technology, 8(19), 1-5.

[8] Radoslaw, K., Turczynski, L., \& Zyla, K. (2016). Comparison of App Inventor 2 and Java in creating personal applications for Android on example of a notepad. Advances in Science and Technology Research Journal, 10(31), 247-254.

[9] Kowalczyk, R., Turczyński, Ł., \& Żyła, K. (2016). Comparison of App Inventor 2 and Java in creating personal applications for Android on example of a notepad. Advances in Science and Technology. Research Journal, 10(31)

[10] Kang, H., Cho, J., \& Kim, H. (2015). Application study on android application prototyping method using app inventor. Indian Journal of Science and Technology, 8(18), 1. 